\title{
The Eastern African Quaternary Research Association (EAQUA) inaugural workshop
}

\author{
Kampala, Uganda, 7-8 June 2007
}

JuLIus B. LeJJu

Mbarara University of Science \& Technology, Uganda; lejju2002@yahoo.co.uk

The first PAGES/Eastern African Quaternary Research Association (EAQUA) workshop was held in Kampala, Uganda, from 7-8 June 2007. The workshop was jointly organized by Mbarara University of Science and Technology, Makerere University, and National Museum of Kenya, and was sponsored by PAGES, INQUA, PAST and BIEA. The EAQUA inaugural workshop was officially launched by Dr. Margaret Avery, the Vice President of the INQUA Commission for Paleoecology and Human Evolution.

This two-day workshop aimed to enhance the growth of the Quaternary science community in eastern and central Africa, through training, promotion of regional collaborative research, and information exchange on Quaternary science research issues. A scientific conference was also held, under the theme "Understanding human-environment interrelationships in the Great Lakes region of central Africa during the late Quaternary", with the aim of understanding the history of human and environment interdependencies in eastern and central Africa, and how environmental variability relates to the cultural and socio-economic changes in the region during the late Quaternary.

The workshop also aimed at fostering dialog among young and senior research scientists from eastern and central Africa, with scholars from developed countries engaged in diverse Quaternary research disciplines. The primary objective of this was to build academic partnerships and enhance Quaternary research capacity in the region.

\section{Workshop participants and paper presentations}

The workshop attracted over 40 participants from ten different countries in eastern and southern Africa, as well as participants from Australia, the UK, Belgium and Sweden. The first day focused on the opening activities, keynote and plenary presentations. Four keynote papers relating to issues of paleoclimate and paleoenvironment in central Africa were presented. The presentations stressed the value of Africa's archives, which range from marine to continental, and lowland to mountain summits, and span millennial to decadal and inter-annual scales. Issues of non-orbital abrupt changes that have

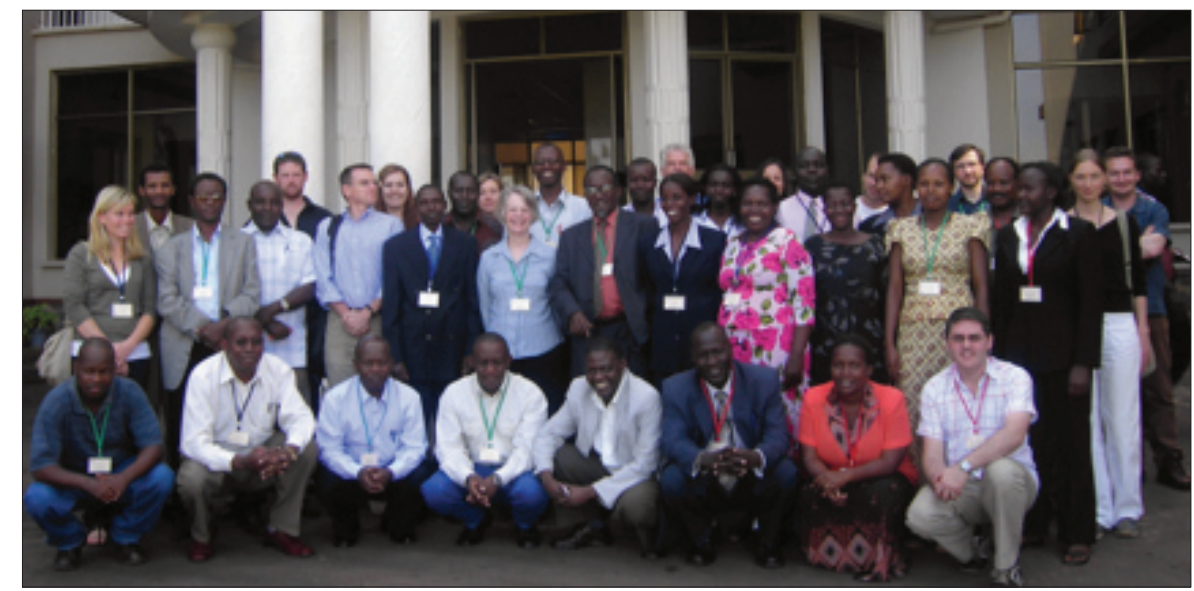

Figure 1: Workshop participants in front of Ridar Hotel

dramatic societal effects, such as El Niño related drought and flood events, were also highlighted.

The Holocene environmental history of this region was discussed. Multi-proxy analyses of sedimentary records, together with historical and archeological data, reported significant changes in environmental conditions in the inter-lacustrine region of central Africa during this time. It was noted that population and land-use change was perfectly correlated, and that as the population continued to grow the arable land size became scarce. Human impact on shallow, fluctuating African lakes has exacerbated the situation. For example, pollution on Lake Victoria has resulted in low water quality as $\mathrm{O}_{2}$ is depleted in the deeper waters.

The keynote session was followed by plenary presentations from scientific organizations (PAST, BIEA, START and WAYSAfrica), who presented brief program backgrounds. The first day was wrapped up with a session of 8 oral and 3 poster paper presentations that addressed paleoclimate and paleoenvironment of central Africa.

The second day focused on the history, archeology and paleontology of the great lakes region, with a total of 7 oral papers and 2 poster presentations. This session discussed issues pertaining to the evolution of anatomically modern humans in eastern Africa and the African continent at large, including the timing and formation of social complexity and technological transformations in the Great Lakes region.

\section{Workshop synthesis and way forward}

The workshop concluded with panel discussions on future research and the way forward. It was agreed that:

- Consultations, linkages and networking among EAQUA members and research institutions on EAQUA activities would be encouraged.

- EAQUA should be strengthened and maintained by making use of local institutional facilities to minimize expenses.

- An EAQUA secretariat and website should be set up for easy circulation of information amongst members and other partners (donors/researchers).

- EAQUA information should be posted on the PAGES and INQUA websites.

- An interim committee will be set up to run EAQUA activities for the next two years before general election (Dr. Julius Lejju and Dr. Mohammed Umer were nominated as Chair and Vice Chair, respectively).

- EAQUA draft constitution will be rectified in the next meeting when membership has been realized.

- The next PAGES/EAQUA workshop should be held in Addis Ababa Ethiopia in 2009. 